\title{
Impact of preoperative wait time on survival in patients with clinical stage II/III gastric cancer
}

\author{
Kenichiro Furukawa ${ }^{1} \cdot$ Tomoyuki Irino $^{1} \cdot$ Rie Makuuchi $^{1} \cdot$ Yusuke Koseki ${ }^{1} \cdot$ Kenichi Nakamura $^{1} \cdot$ Yuhei Waki ${ }^{1}$.

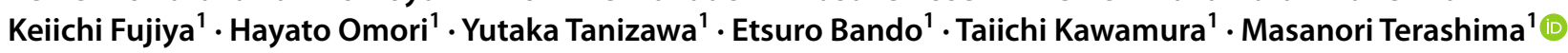

Received: 10 August 2018 / Accepted: 1 December 2018 / Published online: 10 December 2018

(c) The International Gastric Cancer Association and The Japanese Gastric Cancer Association 2018

\begin{abstract}
Background Preoperative wait time is affected by various factors, and a certain time is needed before surgery. There is a concern that cancer treatment delay can lead to poor survival. The present study aimed to evaluate the impact of preoperative wait time on survival in patients with clinical stage (cStage) II/III gastric cancer.

Methods The study included patients with cStage II/III primary gastric cancer undergoing surgery between 2002 and 2012. Preoperative wait time was defined as the time from endoscopy for initial diagnosis to surgery. Patients were divided into the following three groups according to wait time: short wait group ( $\leq 30$ days), intermediate wait group ( $>30$ and $\leq 60$ days), and long wait group ( $>60$ and $\leq 90$ days). Patient characteristics and survival were compared among the groups.

Results This study included 467 male (67\%) and 229 female (33\%) patients, and the median patient age was 67 years. The numbers of cStage II and III patients were 332 (48\%) and 364 (52\%), respectively. The median wait time was 45 days. The body mass index was lower in the short wait group than in the other groups. A shorter wait time tended to be associated with a more advanced cStage. Although survival was significantly worse in the short wait group than in the long wait group, wait time was not identified as an independent prognostic factor in multivariate analysis.

Conclusion Preoperative wait time up to 90 days does not affect survival in patients with cStage II/III gastric cancer.
\end{abstract}

Keywords Gastric cancer $\cdot$ Preoperative wait time $\cdot$ Surgery $\cdot$ Survival

\section{Introduction}

Preoperative wait time in cancer patients is affected by various factors, including patient-, provider-, and health systemrelated factors. Patient-related factors include cancer staging, assessment and treatment of comorbidities before surgery, and nutritional support for those with malnutrition. Providerrelated factors include capacity limits of the examination and operation. Health system-related factors include the recommendation of maximum pretreatment time by several

Electronic supplementary material The online version of this article (https://doi.org/10.1007/s10120-018-00910-y) contains supplementary material, which is available to authorized users.

Masanori Terashima

m.terashima@scchr.jp

1 Division of Gastric Surgery, Shizuoka Cancer Center, 1007 Shimonagakubo, Nagaizumi-cho, Sunto-gun, Shizuoka 411-8777, Japan countries [1,2] and medical insurance [3]. Therefore, there is a certain wait time before cancer surgery.

There is a concern that a delay in cancer treatment can lead to a poor survival outcome. Indeed, previous large cohort studies showed an association between a long preoperative wait time and poor survival in breast cancer patients [4-7]. However, such a tendency has not been shown in other cancer types, including gastric cancer. Only one previous report evaluated the association between preoperative wait time and survival in gastric cancer patients. However, the results were inconclusive owing to non-adjustment of patient stage [6].

Thus, the present study aimed to evaluate the impact of preoperative wait time on survival in patients with clinical stage (cStage) II/III gastric cancer. 


\section{Patients and methods}

\section{Definition of preoperative wait time}

Preoperative wait time was defined as the time from endoscopy for the initial diagnosis of gastric cancer to surgery. In Japan, most patients first visit the clinic or territorial hospital because of abnormal findings in a health checkup or symptoms and subsequently undergo endoscopy. After the diagnosis of gastric cancer, they are referred to hospitals that can perform precise preoperative examinations and surgery.

In this study, patients were divided into the following three groups according to preoperative wait time: short wait group ( $\leq 30$ days), intermediate wait group ( $>30$ and $\leq 60$ days), and long wait group ( $>60$ and $\leq 90$ days). Patient characteristics and survival outcomes were compared among the groups.

\section{Patients and data collection}

This study included patients who underwent surgery for cStage II/III primary gastric cancer between January 2002 and December 2012. The exclusion criteria were as follows: (1) previous endoscopic submucosal dissection for the primary lesion, (2) preoperative chemotherapy, (3) peritoneal metastasis or positive peritoneal cytology as found by staging laparoscopy, (4) active duplicated cancer, (5) special histological tumor types, excluding lymphoid stroma, (6) urgent symptoms, (7) Eastern Cooperative Oncology Group Performance Status of two or more, and (8) unevaluable preoperative wait time. Staging laparoscopy was performed in the following patients since July 2008, as previously reported: (1) patients with type 4 or large $(\geq 8 \mathrm{~cm})$ type 3 gastric cancer, (2) patients included in neoadjuvant chemotherapy trials, such as those with bulky lymph node swelling (one lymph node larger than $3 \mathrm{~cm}$ or two lymph nodes larger than $1.5 \mathrm{~cm}$ ) around the celiac axis or para-aortic lymph node swelling, and (3) patients with findings suggestive of peritoneal metastasis, such as ascites and peritoneal nodules [8,9]. Urgent symptoms were defined as symptoms that needed hospitalization or interventions, such as bleeding, gastric outlet obstruction, and ileus. Additionally, patients with a preoperative wait time of more than 90 days were excluded from the analysis, because most of them had special reasons for a long preoperative wait time.

Clinicopathological data were collected from a prospectively recorded database or electronic medical records. The Charlson Comorbidity Index was used to evaluate comorbidities [10]. For clinical staging, gastroscopy with biopsy, upper gastrointestinal tract contrast radiography, and contrast-enhanced multi-detector computed tomography (CT) were always performed. The cStage was confirmed by a cancer board that included surgeons, gastroenterologists, radiologists, and endoscopists, according to the Japanese Classification of Gastric Carcinoma as previously reported $[11,12]$. Endoscopic ultrasonography, gastric cancerspecific protocol CT, and positron emission tomography/ computed tomography (PET-CT) were not routinely performed in our hospital. Treatment, including surgery, and follow-up were performed according to the Japanese Gastric Cancer Treatment Guidelines [13]. Adjuvant chemotherapy with $\mathrm{S}-1$ has been administered to pathological stage (pStage) II/III patients since October 2007 after the ACTS-GC trial [14].

\section{Statistical analysis}

All continuous variables are presented as median [interquartile range (IQR)]. The Kruskal-Wallis test and Wilcoxon rank sum test were performed. Survival time was calculated from the date of cancer diagnosis by endoscopy to the date of the last hospital visit or death, and it was analyzed using the Kaplan-Meier method. The log-rank test was used to compare the groups. Bonferroni correction was used in multiple comparisons. To identify the independent prognostic factors, univariate and multivariate analyses for overall survival (OS) were conducted using the Cox-proportional hazards model. All statistical analyses were performed using R Statistics version 3.3.3 (R Foundation for Statistical Computing, Vienna, Austria). A two-sided $P$ value $<0.05$ $(<0.017$ in multiple comparisons of the three groups) was considered significant.

\section{Ethical approval}

The present study was approved by the institutional review board of Shizuoka Cancer Center (approval no. 28-J171-28-1-3).

\section{Results}

\section{Patient characteristics}

The CONSORT diagram of this study is shown in Fig. 1. Between January 2002 and December 2012, 1282 patients underwent surgery for cStage II/III primary gastric cancer. Among these patients, 696 (54\%) were included in this study.

The characteristics of the patients and clinical data are presented in Table 1 . There were 467 male and 229 female patients, and the median patient age was 67 years. The 
Underwent surgery for clinical stage II/III primary gastric cancer

between January 2002 and December $2012(n=1282)$

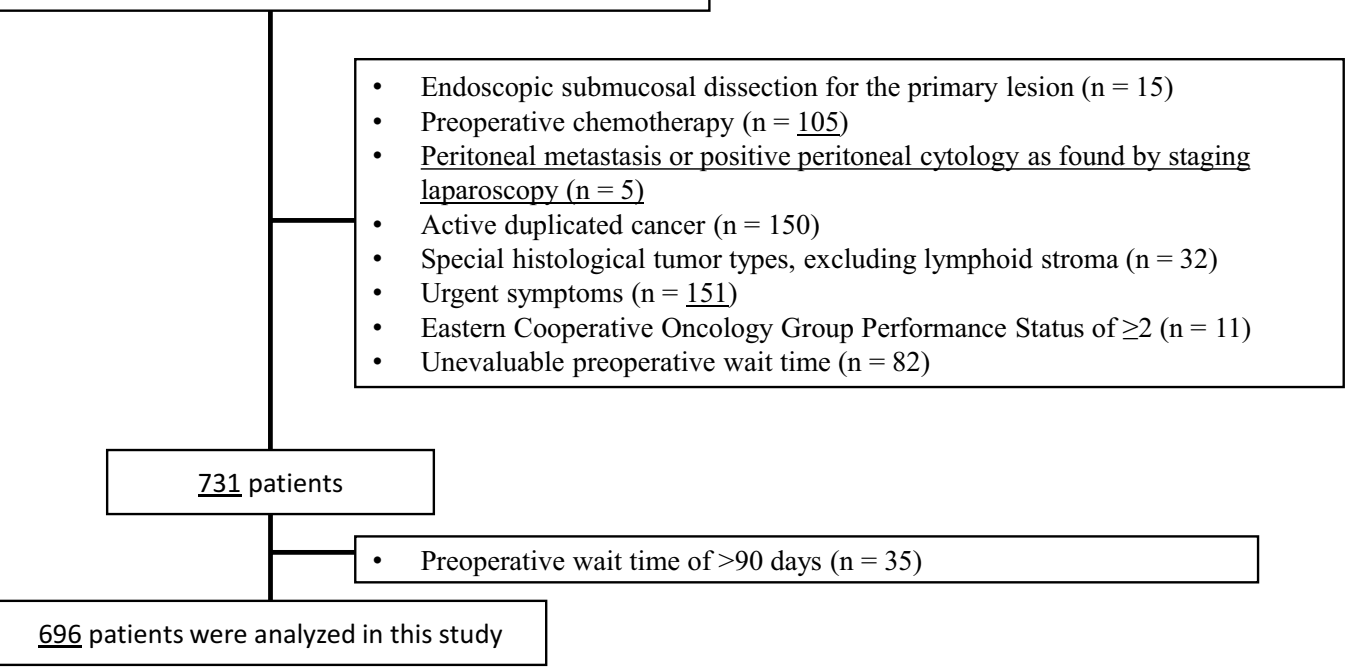

Fig. 1 CONSORT flow chart of this study

numbers of cStage II and III patients were 332 and 364, respectively.

The median preoperative wait time was 45 days (IQR 35-57 days). The histogram of the preoperative wait time is presented in Fig. 2. The short, intermediate, and long wait groups included 103 (15\%), 457 (66\%), and $136(20 \%)$ patients, respectively.

The body mass index and albumin level were lower in the short wait group than in the other groups. Furthermore, the hemoglobin level was lower, and comorbidity was less frequent in the short wait group than in the long wait group. The frequency of macroscopic type 4 tumors was higher in the short and intermediate wait group than in the long wait group. A shorter wait time tended to be associated with a more advanced cStage. There were no differences in age, sex, histological tumor type, preoperative tumor location, and gastrectomy type among the groups. With regard to postoperative histopathological factors, residual tumor and advanced pStage were more common in the short wait group than in the long wait group (Table 1). The reasons for pStage IV disease were as follows: peritoneal metastasis (88 patients: $48 \%$ ), positive peritoneal cytology (91 patients: $49 \%$ ), liver metastasis (3 patients: $2 \%$ ), extraregional lymph node metastasis (3 patients: $2 \%$ ), and unknown (1 patient: $0 \%)$. The primary reason for $\mathrm{R} 2$ resection was peritoneal metastasis (67 patients: $74 \%$ ).

\section{Overall survival of the patients in the wait groups}

OS curves are presented in Fig. 3. Survival was worse in the short wait group than in the long wait group (Fig. 3a). OS curves stratified by cStage were compared among the groups. For cStage II, survival was worse in the intermediate wait group than in the long wait group (Fig. 3b). However, for cStage III, there were no significant differences in survival among the groups (Fig. 3c).

OS curves stratified by pStage II-IV are presented in Fig. 4. The survival for each pStage was not different among the wait groups.

\section{Univariate and multivariate analyses for OS}

Table 2 shows the results of the univariate and multivariate analyses for OS. The multivariate analysis identified age $>70$ years, $\mathrm{BMI}>22 \mathrm{~kg} / \mathrm{m}^{2}$, comorbidities, preoperative albumin level $>4.0 \mathrm{~g} / \mathrm{dL}$, undifferentiated histological type, preoperative macroscopic type 4 tumor, and advanced cStage as independent prognostic factors. There were significant differences in survival among the wait groups. However, preoperative wait time was not identified as an independent prognostic factor.

Table S1 shows the results of the multivariate analysis for OS after the introduction of S-1 adjuvant chemotherapy (since November 2007). The preoperative wait time was not identified as an independent prognostic factor in these patients.

\section{Discussion}

The present study found that preoperative wait time up to 90 days did not affect the survival of patients with cStage II/III gastric cancer. 
Table 1 Patient characteristics

\begin{tabular}{|c|c|c|c|c|c|c|c|}
\hline \multirow[t]{2}{*}{ Characteristic } & \multirow{2}{*}{$\begin{array}{l}\text { Total }(n=696) \\
n(\%)\end{array}$} & \multicolumn{3}{|c|}{ Preoperative wait time } & \multicolumn{3}{|c|}{$P$ value (multiple comparisons $* *$ ) } \\
\hline & & $\begin{array}{l}\text { Short }(n=103) \\
n(\%)\end{array}$ & $\begin{array}{l}\text { Intermediate }(n=457) \\
n(\%)\end{array}$ & $\begin{array}{l}\text { Long }(n=136) \\
n(\%)\end{array}$ & $\begin{array}{l}\text { Short vs. } \\
\text { intermedi- } \\
\text { ate }\end{array}$ & Short vs. long & $\begin{array}{l}\text { Interme- } \\
\text { diate vs. } \\
\text { long }\end{array}$ \\
\hline Age (years) & & & & & 0.598 & 0.311 & 0.468 \\
\hline Median & 67 & 66 & 67 & 68 & & & \\
\hline IQR & $59-74$ & $59-73$ & $58-74$ & $60-74$ & & & \\
\hline Sex & & & & & 0.816 & 0.582 & 0.756 \\
\hline Male & $467(67)$ & $71(69)$ & $307(67)$ & $89(65)$ & & & \\
\hline Female & $229(33)$ & $32(31)$ & $150(33)$ & $47(35)$ & & & \\
\hline BMI $\left(\mathrm{kg} / \mathrm{m}^{2}\right)$ & & & & & 0.005 & 0.013 & 0.736 \\
\hline Median & 22.2 & 21.6 & 22.4 & 22.2 & & & \\
\hline IQR & $20.3-24.3$ & $19.7-23.2$ & $20.3-24.4$ & $20.7-24.5$ & & & \\
\hline Charlson Comorbidity Index & & & & & 0.016 & 0.020 & 0.661 \\
\hline$\geq 1$ & $177(25)$ & $16(16)$ & $122(27)$ & $39(29)$ & & & \\
\hline 0 & $519(75)$ & $87(84)$ & $335(73)$ & $97(71)$ & & & \\
\hline Preoperative albumin (g/dL) & & & & & 0.001 & $<0.001$ & 0.238 \\
\hline Median & 4.1 & 4 & 4.2 & 4.2 & & & \\
\hline IQR & $3.8-4.4$ & $3.6-4.2$ & $3.8-4.4$ & $3.9-4.5$ & & & \\
\hline $\begin{array}{l}\text { Preoperative hemoglobin } \\
(\mathrm{g} / \mathrm{dL})\end{array}$ & & & & & 0.064 & 0.003 & 0.045 \\
\hline Median & 12.9 & 12.4 & 12.9 & 13.3 & & & \\
\hline IQR & $11.2-14.3$ & $10.6-13.9$ & $11.1-14.3$ & $11.8-14.5$ & & & \\
\hline Histology $(n)$ & & & & & 0.578 & 0.353 & 0.553 \\
\hline Differentiated type & $282(41)$ & $38(37)$ & $185(40)$ & $59(43)$ & & & \\
\hline Undifferentiated type & $414(59)$ & $65(63)$ & $272(60)$ & $77(57)$ & & & \\
\hline $\begin{array}{l}\text { Preoperative tumor location } \\
\quad(n)\end{array}$ & & & & & 0.637 & 0.735 & 0.576 \\
\hline $\begin{array}{l}\text { Upper third of the stomach/ } \\
\text { esophagus }\end{array}$ & $237(34)$ & $39(38)$ & $152(33)$ & $46(34)$ & & & \\
\hline Middle third of the stomach & $241(35)$ & $33(32)$ & $165(36)$ & $43(32)$ & & & \\
\hline Lower third of the stomach & $218(31)$ & $31(30)$ & $140(31)$ & $47(35)$ & & & \\
\hline $\begin{array}{l}\text { Preoperative macroscopic } \\
\text { type }(n)\end{array}$ & & & & & 0.483 & 0.005 & 0.005 \\
\hline Type 4 & $64(9)$ & $13(13)$ & $47(10)$ & $4(3)$ & & & \\
\hline Not type 4 & $632(91)$ & $90(87)$ & $410(90)$ & $132(97)$ & & & \\
\hline $\begin{array}{l}\text { Preoperative tumor size } \\
\quad(\mathrm{mm})\end{array}$ & & & & & 0.006 & $<0.001$ & $<0.001$ \\
\hline Median & 50 & 60 & 50 & 40 & & & \\
\hline IQR & $40-70$ & $50-80$ & $40-70$ & $35-60$ & & & \\
\hline Clinical stage $(n)$ & & & & & $<0.001$ & $<0.001$ & 0.011 \\
\hline IIA & $127(18)$ & $10(10)$ & $79(17)$ & $38(28)$ & & & \\
\hline IIB & $205(29)$ & $14(14)$ & $147(32)$ & $44(32)$ & & & \\
\hline IIIA & $123(18)$ & $24(23)$ & $75(16)$ & $24(18)$ & & & \\
\hline IIIB & $160(23)$ & $27(26)$ & $115(25)$ & $18(13)$ & & & \\
\hline IIIC & $81(12)$ & $28(27)$ & $41(9)$ & $12(9)$ & & & \\
\hline Type of gastrectomy $(n)$ & & & & & 0.115 & 0.144 & 0.198 \\
\hline Total gastrectomy & $312(45)$ & $53(51)$ & $203(44)$ & $56(41)$ & & & \\
\hline Distal gastrectomy & $348(50)$ & $43(42)$ & $230(50)$ & $75(55)$ & & & \\
\hline Others & $2(0)$ & $1(1)$ & 0 & $1(1)$ & & & \\
\hline Not resected & $34(5)$ & $6(6)$ & $24(5)$ & $4(3)$ & & & \\
\hline
\end{tabular}


Table 1 (continued)

\begin{tabular}{|c|c|c|c|c|c|c|c|}
\hline \multirow[t]{2}{*}{ Characteristic } & \multirow{2}{*}{$\begin{array}{l}\text { Total }(n=696) \\
n(\%)\end{array}$} & \multicolumn{3}{|c|}{ Preoperative wait time } & \multicolumn{3}{|c|}{$P$ value (multiple comparisons $* *$ ) } \\
\hline & & $\begin{array}{l}\text { Short }(n=103) \\
n(\%)\end{array}$ & $\begin{array}{l}\text { Intermediate }(n=457) \\
n(\%)\end{array}$ & $\begin{array}{l}\text { Long }(n=136) \\
n(\%)\end{array}$ & $\begin{array}{l}\text { Short vs. } \\
\text { intermedi- } \\
\text { ate }\end{array}$ & Short vs. long & $\begin{array}{l}\text { Interme- } \\
\text { diate vs. } \\
\text { long }\end{array}$ \\
\hline Residual tumor $(n)$ & & & & & 0.191 & 0.005 & 0.028 \\
\hline R0 & $503(72)$ & $66(64)$ & $325(71)$ & $112(82)$ & & & \\
\hline $\mathrm{R} 1$ & $103(15)$ & $17(17)$ & $74(16)$ & $12(9)$ & & & \\
\hline $\mathrm{R} 2$ & $90(13)$ & $20(19)$ & $58(13)$ & $12(9)$ & & & \\
\hline Pathological stage $(n)$ & & & & & 0.028 & $<0.001$ & 0.019 \\
\hline IA & $28(4)$ & 0 & $19(4)$ & $9(7)$ & & & \\
\hline IB & $44(6)$ & $1(1)$ & $31(7)$ & $12(9)$ & & & \\
\hline IIA & $90(13)$ & $13(13)$ & $57(12)$ & $20(15)$ & & & \\
\hline IIB & $97(14)$ & $12(12)$ & $57(12)$ & $28(21)$ & & & \\
\hline IIIA & $82(12)$ & $13(13)$ & $56(12)$ & $13(10)$ & & & \\
\hline IIIB & $101(15)$ & $20(19)$ & $59(13)$ & $22(16)$ & & & \\
\hline IIIC & $66(9)$ & $8(8)$ & $50(11)$ & $8(6)$ & & & \\
\hline IV & $186(27)$ & $36(35)$ & $127(28)$ & $23(17)$ & & & \\
\hline Unknown & $2(0)$ & 0 & $1(0)$ & $1(1)$ & & & \\
\hline
\end{tabular}

$I Q R$ Interquartile range, $B M I$ body mass index

$* * P<0.017$ was considered significant

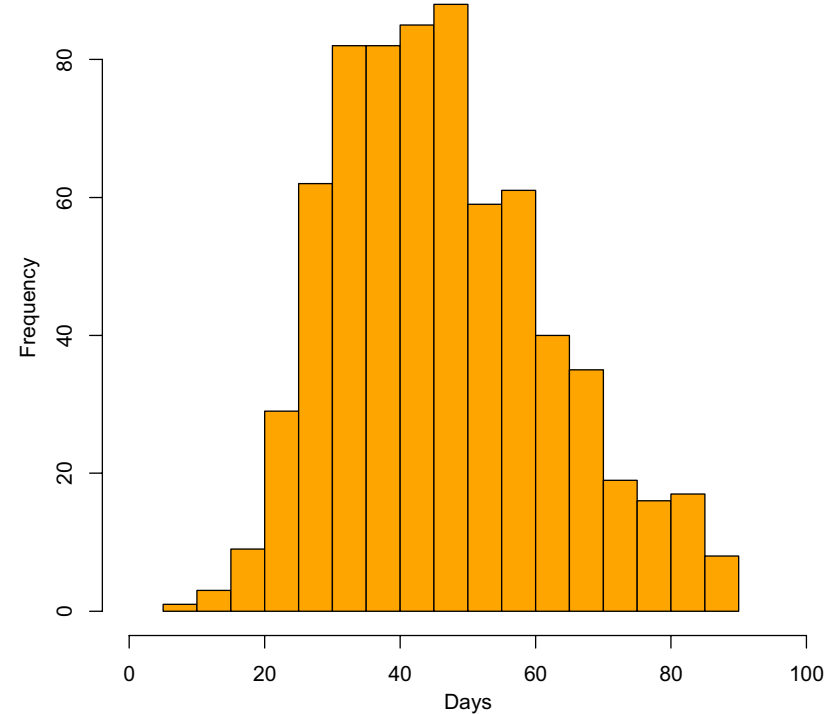

Fig. 2 Histogram of the preoperative wait time. The median wait time was 45 days (interquartile range $35-57$ days)

In this study, patient characteristics differed according to preoperative wait time. Specifically, a shorter wait time tended to be associated with a more advanced cStage. In addition, the body mass index and albumin level were lower in the short wait group than in the other groups. Previous studies showed that an advanced cStage and low body mass index were associated with poor survival in gastric cancer $[12,15]$. Thus, patients with a short wait time had many poor prognostic factors. Indeed, survival was significantly worse in the short wait group than in the long wait group, and this has been called the "waiting time paradox" [16]. Several previous studies showed that patients with a short preoperative wait time had advanced cancer stage, high tumor marker levels, less frequent $\mathrm{R} 0$ resection, and low body mass index, which were negative prognostic factors, resulting in poor survival [3, 16-18]. This might be because surgeons tend to prioritize treatment for patients with a poor prognosis. In this study, patients with a short wait time needed early surgery owing to symptoms associated with the tumor, such as bleeding and gastric outlet obstruction. Therefore, when comparing survival according to preoperative wait time, it is necessary to adjust patient background.

In multivariate analysis, preoperative wait time was not an independent prognostic factor for survival. Our result is consistent with the finding in the study by Yun et al. [6] This previous study was a large-scale cohort study that analyzed 66,825 patients who underwent surgery as the first definite treatment; however, they did not adjust for cancer stage [6]. The authors reported that a preoperative wait time of more than 31 days was not associated with poor survival in patients with gastric cancer [6].

The association between pretreatment wait time and survival is not identical among cancer types. The preoperative wait time has been demonstrated to have no impact on survival in many cancers, such as lung, pancreas, prostate, bladder, and cervical cancers [6, 19-22]. 

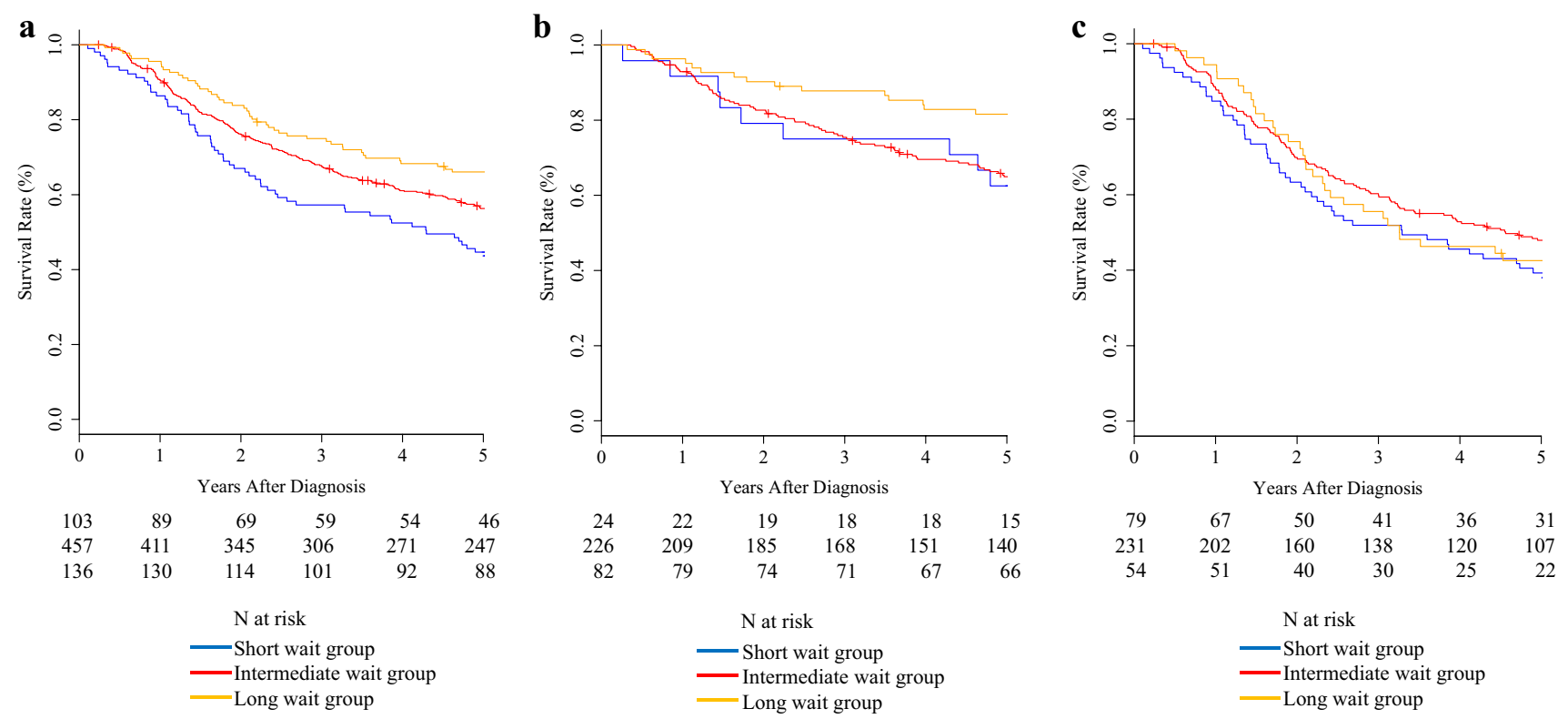

Fig. 3 a Overall survival curves for the wait groups among all patients. Survival was worse in the short wait group than in the long wait group (5-year survival rate: short wait group $44.7 \%$; intermediate wait group $56.3 \%$; long wait group $66.0 \%$; short vs. intermediate wait group: $P=0.019$; short vs. long wait group: $P<0.001$; intermediate vs. long wait group: $P=0.034$ ). b Overall survival curves for the wait groups among clinical stage II patients. Survival was worse in the intermediate wait group than in the long wait group (5-year survival rate: short wait group $62.5 \%$; intermediate wait group $64.9 \%$; long wait group $81.6 \%$; short vs. intermediate wait group: $P=0.822$; short vs. long wait group: $P=0.103$; intermediate vs. long wait group: $P=0.004)$. c Overall survival curves for the wait groups among clinical stage III patients. There are no differences in survival among the groups (5-year survival rate: short wait group 39.2\%; intermediate wait group $47.9 \%$; long wait group $42.5 \%$; short vs. intermediate wait group: $P=0.083$; short vs. long wait group: $P=0.487$; intermediate vs. long wait group: $P=0.541$ )

time on survival is controversial in patients with colorectal cancer. Yun et al. reported that a preoperative wait time of more than 31 days was associated with poor survival [6]. Additionally, Shin et al. reported that survival was worse among patients with a preoperative wait time of more than 84 days than among those with a preoperative wait time of between 7 and 29 days [7]. However, in this report, the sample size was not sufficient to obtain a definitive conclusion. Conversely, Roland et al. found no association between pretreatment wait time and survival [23]. A significant correlation between preoperative wait time and survival has been demonstrated in only breast cancer [4-7]. Bleicher et al. reported that OS worsened with increasing preoperative wait time in five intervals $(\leq 30$, 31-60, 61-90, 91-120, and 121-180 days) [4]. Eriksson et al. reported a linear association between preoperative wait time and survival [5]. Hence, there are varying results with regard to the association between preoperative wait time and survival among cancer types, and this is probably because of different tumor characteristics and different treatments.

Clinical staging can be improved, although the rate of pStage IV in this study is comparable to that in a previous report. Kim et al. reported that of 498 patients with gastric

with stage IA-IIA cervical cancer who underwent surgic resection [22]. However, the impact of preoperative wait 



Fig. 4 a Overall survival curves for the wait groups among pathological stage II patients. There are no differences in survival among the groups (5-year survival rate: short wait group 76.0\%; intermediate wait group $82.2 \%$; long wait group $85.3 \%$; short vs. intermediate wait group: $P=0.323$; short vs. long wait group: $P=0.115$; intermediate vs. long wait group: $P=0.264$ ). b Overall survival curves for the wait groups among pathological stage III patients. There are no differences in survival among the groups (5-year survival rate: short wait group 53.7\%; intermediate wait group 59.3\%; long wait group

cancer whose tumor invasion was pathological T2 or more, 154 patients (31\%) had pStage IV disease [24]. To avoid $\mathrm{R} 2$ resection, we performed staging laparoscopy, which was reported to have identified peritoneal metastasis in $34-47 \%$ of locally advanced gastric cancers since July 2008 [8, 9]. In this study, peritoneal metastasis or positive peritoneal cytology were detected in 5 of $33(15 \%)$ patients by staging laparoscopy.

It was unavoidable to include pStage IV patients in this study because we wanted to evaluate the impact of preoperative wait time on survival in patients with cStage II/III gastric cancers. We believe that the true impact of preoperative wait time on survival would have been overlooked if these patients had been excluded from this study.

The results of this study do not imply that treatment should be delayed without reason. A prolonged pretreatment wait time has been shown to cause psychological distress [25] and deteriorated quality of life and satisfaction [26], and it is associated with frequent psychiatric hospital care after treatment in patients with preexisting mental disorders
$60.5 \%$; short vs. intermediate wait group: $P=0.741$; short vs. long wait group: $P=0.861$; intermediate vs. long wait group: $P=0.869)$. c Overall survival curves for the wait groups among pathological stage IV patients. There are no differences in survival among the groups (5-year survival rate: short wait group $11.1 \%$; intermediate wait group $15.4 \%$; long wait group $8.7 \%$; short vs. intermediate wait group: $P=0.197$; short vs. long wait group: $P=0.636$; intermediate vs. long wait group: $P=0.659$ )

[27]. If a prolonged preoperative wait time is needed for the assessment and control of comorbidities, surgeons should pay close attention and should start treatment as early as possible.

The present study has some limitations. First, our cohort did not include patients who underwent neoadjuvant chemotherapy (NAC). NAC is not a standard approach for the treatment of locally advanced gastric cancer in Japan and is now being investigated in clinical trials. If NAC becomes a standard treatment in the future, the impact of preoperative wait time on survival should be investigated in patients receiving NAC. Second, patients with a preoperative wait time of more than 90 days were excluded from the study. However, in our hospital, the number of patients with a long wait time of more than 90 days was low (3\%), and most of the patients had special reasons for delay, such as severe comorbidities requiring operation and complicated familial reasons. Therefore, the upper limit of 90 days for preoperative wait time appears reasonable. 
Table 2 Univariate and multivariate analyses for the identification of independent prognostic factors for overall survival in all clinical stage gastric cancer cases

\begin{tabular}{|c|c|c|c|c|c|c|c|c|}
\hline & \multicolumn{4}{|c|}{ Univariate } & \multicolumn{4}{|c|}{ Multivariate } \\
\hline & \multirow[t]{2}{*}{ HR } & \multicolumn{2}{|c|}{$95 \% \mathrm{CI}$} & \multirow[t]{2}{*}{$P$ value } & \multirow[t]{2}{*}{ HR } & \multicolumn{2}{|c|}{$95 \% \mathrm{CI}$} & \multirow[t]{2}{*}{$P$ value } \\
\hline & & Lower & Upper & & & Lower & Upper & \\
\hline \multicolumn{9}{|l|}{ Preoperative wait time (days) } \\
\hline$\leq 30$ & 1.000 & & & & 1.000 & & & \\
\hline$>30$ and $\leq 60$ & 0.714 & 0.538 & 0.949 & 0.020 & 0.894 & 0.659 & 1.212 & 0.471 \\
\hline$>60$ and $\leq 90$ & 0.515 & 0.355 & 0.747 & $<0.001$ & 0.801 & 0.541 & 1.188 & 0.270 \\
\hline Age ( $\leq 70$ vs. $>70$ years) & 1.645 & 1.325 & 2.043 & $<0.001$ & 1.691 & 1.344 & 2.128 & $<0.001$ \\
\hline Sex (female vs. male) & 1.092 & 0.869 & 1.373 & 0.451 & 1.058 & 0.831 & 1.349 & 0.647 \\
\hline $\mathrm{BMI}\left(\leq 22\right.$ vs. $\left.>22 \mathrm{~kg} / \mathrm{m}^{2}\right)$ & 0.701 & 0.565 & 0.869 & 0.001 & 0.800 & 0.640 & 1.000 & 0.049 \\
\hline Charlson Comorbidity Index ( 0 vs. $\geq 1)$ & 1.382 & 1.092 & 1.750 & 0.007 & 1.400 & 1.093 & 1.794 & 0.008 \\
\hline Preoperative albumin $(\leq 4.0$ vs. $>4.0 \mathrm{~g} / \mathrm{dL})$ & 0.502 & 0.405 & 0.623 & $<0.001$ & 0.707 & 0.557 & 0.897 & 0.004 \\
\hline Preoperative hemoglobin ( $\leq 12$ vs. $>12$ g/dL) & 0.852 & 0.668 & 1.087 & 0.197 & 1.031 & 0.794 & 1.338 & 0.819 \\
\hline Histology (differentiated type vs. undifferentiated type) & 1.481 & 1.180 & 1.858 & $<0.001$ & 1.627 & 1.280 & 2.070 & $<0.001$ \\
\hline \multicolumn{9}{|l|}{ Preoperative tumor location } \\
\hline Upper third of the stomach/esophagus & 1.000 & & & & 1.000 & & & \\
\hline Middle third of the stomach & 0.673 & 0.519 & 0.873 & 0.003 & 0.853 & 0.650 & 1.119 & 0.252 \\
\hline Lower third of the stomach & 0.747 & 0.576 & 0.968 & 0.028 & 0.946 & 0.719 & 1.244 & 0.690 \\
\hline Preoperative macroscopic type (not type 4 vs. type 4 ) & 2.666 & 1.965 & 3.616 & $<0.001$ & 2.401 & 1.716 & 3.359 & $<0.001$ \\
\hline Preoperative tumor size ( $\leq 50$ vs. $>50 \mathrm{~mm}$ ) & 1.328 & 1.062 & 1.660 & 0.013 & 0.968 & 0.768 & 1.222 & 0.786 \\
\hline \multicolumn{9}{|l|}{ cStage } \\
\hline IIA & 1.000 & & & & 1.000 & & & \\
\hline IIB & 2.237 & 1.463 & 3.421 & $<0.001$ & 1.971 & 1.275 & 3.046 & 0.002 \\
\hline IIIA & 2.813 & 1.804 & 4.387 & $<0.001$ & 2.469 & 1.565 & 3.893 & $<0.001$ \\
\hline IIIB & 3.452 & 2.263 & 5.266 & $<0.001$ & 3.335 & 2.148 & 5.178 & $<0.001$ \\
\hline IIIC & 5.466 & 3.478 & 8.591 & $<0.001$ & 4.761 & 2.939 & 7.713 & $<0.001$ \\
\hline
\end{tabular}

BMI Body mass index

In conclusion, preoperative wait time up to 90 days does not affect survival in patients with cStage II/III gastric cancer.

Funding This study was funded by National Cancer Center Research and Development Fund (29-4-3).

\section{Compliance with ethical standards}

Ethical standards All procedures followed were in accordance with the ethical standards of responsible committees on human experimentation (institutional and national) and with the Helsinki Declaration of 1964 and later versions. Informed consent or an appropriate substitute was obtained.

Conflict of interest Author MT has received research grants from Taiho Pharmaceutical Co. Ltd., Chugai Pharmaceutical company, Eli Lilly Japan, Ono Pharmaceutical company, Bristol Myers Squib Japan, and Yakult Honsha Co., Ltd. Author EB has received research grants from EIZO Corporation, Kanehara-Shuppan, TERUMO CORPORATION, and EIZAI.

\section{References}

1. Cancer Research UK. Cancer waiting times. https://www.cance rresearchuk.org/about-cancer/cancer-in-general/treatment/acces s-to-treatment/waiting-times-after-diagnosis.

2. Visser E, Leeftink AG, van Rossum PS, Siesling S, van Hillegersberg R, Ruurda JP. Waiting time from diagnosis to treatment has no impact on survival in patients with esophageal cancer. Ann Surg Oncol. 2016;23:2679-89.

3. Bilimoria KY, Ko CY, Tomlinson JS, Stewart AK, Talamonti MS, Hynes DL, et al. Wait times for cancer surgery in the United States: trends and predictors of delays. Ann Surg. 2011;253:779-85.

4. Bleicher RJ, Ruth K, Sigurdson ER, Beck JR, Ross E, Wong YN, et al. Time to surgery and breast cancer survival in the United States. JAMA Oncol. 2016;2:330-9.

5. Eriksson L, Bergh J, Humphreys K, Warnberg F, Tornberg S, Czene K. Time from breast cancer diagnosis to therapeutic surgery and breast cancer prognosis: a population-based cohort study. Int J Cancer. 2018;143:1093-104.

6. Yun YH, Kim YA, Min YH, Park S, Won YJ, Kim DY, et al. The influence of hospital volume and surgical treatment delay on longterm survival after cancer surgery. Ann Oncol. 2012;23:2731-7. 
7. Shin DW, Cho J, Kim SY, Guallar E, Hwang SS, Cho B, et al. Delay to curative surgery greater than 12 weeks is associated with increased mortality in patients with colorectal and breast cancer but not lung or thyroid cancer. Ann Surg Oncol. 2013;20:2468-76.

8. Miki Y, Tokunaga M, Tanizawa Y, Bando E, Kawamura T, Terashima M. Staging laparoscopy for patients with cM0, Type 4, and large Type 3 gastric cancer. World J Surg. 2015;39:2742-7.

9. Irino T, Sano T, Hiki N, Ohashi M, Nunobe S, Kumagai K, et al. Diagnostic staging laparoscopy in gastric cancer: a prospective cohort at a cancer institute in Japan. Surg Endosc. 2018;32:268-75.

10. Charlson ME, Pompei P, Ales KL, MacKenzie CR. A new method of classifying prognostic comorbidity in longitudinal studies: development and validation. J Chronic Dis. 1987;40:373-83.

11. Japanese Gastric Cancer Association. Japanese classification of gastric carcinoma: 3rd English edition. Gastric Cancer. 2011;14:101-12.

12. Bando E, Makuuchi R, Tokunaga M, Tanizawa Y, Kawamura T, Terashima M. Impact of clinical tumor-node-metastasis staging on survival in gastric carcinoma patients receiving surgery. Gastric Cancer. 2017;20:448-56.

13. Japanese Gastric Cancer Association. Japanese gastric cancer treatment guidelines 2010 (ver. 3). Gastric Cancer. 2011;14:113-23.

14. Sakuramoto S, Sasako M, Yamaguchi T, Kinoshita T, Fujii M, Nashimoto A, et al. Adjuvant chemotherapy for gastric cancer with S-1, an oral fluoropyrimidine. N Engl J Med. 2007;357:1810-20.

15. Feng F, Zheng G, Guo X, Liu Z, Xu G, Wang F, et al. Impact of body mass index on surgical outcomes of gastric cancer. BMC Cancer. 2018;18:151.

16. Crawford SC, Davis JA, Siddiqui NA, de Caestecker L, Gillis $\mathrm{CR}$, Hole D, et al. The waiting time paradox: population based retrospective study of treatment delay and survival of women with endometrial cancer in Scotland. BMJ. 2002;325:196.

17. Kotz BS, Croft S, Ferry DR. Do delays between diagnosis and surgery in resectable oesophageal cancer affect survival? A study based on West Midlands cancer registration data. Br J Cancer. 2006;95:835-40.
18. Matsuo K, Opper NR, Ciccone MA, Garcia J, Tierney KE, Baba $\mathrm{T}$, et al. Time interval between endometrial biopsy and surgical staging for type I endometrial cancer: association between tumor characteristics and survival outcome. Obstet Gynecol. 2015;125:424-33.

19. Diaconescu R, Lafond C, Whittom R. Treatment delays in nonsmall cell lung cancer and their prognostic implications. J Thorac Oncol. 2011;6:1254-9.

20. Korets R, Seager CM, Pitman MS, Hruby GW, Benson MC, McKiernan JM. Effect of delaying surgery on radical prostatectomy outcomes: a contemporary analysis. BJU Int. 2012;110:211-6.

21. Gulliford MC, Petruckevitch A, Burney PG. Survival with bladder cancer, evaluation of delay in treatment, type of surgeon, and modality of treatment. BMJ. 1991;303:437-40.

22. Umezu T, Shibata K, Kajiyama H, Yamamoto E, Mizuno M, Kikkawa F. Prognostic factors in stage IA-IIA cervical cancer patients treated surgically: does the waiting time to the operation affect survival? Arch Gynecol Obstet. 2012;285:493-7.

23. Roland CL, Schwarz RE, Tong L, Ahn C, Balch GC, Yopp AC, et al. Is timing to delivery of treatment a reliable measure of quality of care for patients with colorectal adenocarcinoma? Surgery. 2013;154:421-8.

24. Kim SJ, Kim HH, Kim YH, Hwang SH, Lee HS, Park DJ, et al. Peritoneal metastasis: detection with 16- or 64-detector row CT in patients undergoing surgery for gastric cancer. Radiology. 2009;253:407-15.

25. Gray RE, Fitch MI, Phillips C, Labrecque M, Klotz L. Presurgery experiences of prostate cancer patients and their spouses. Cancer Pract. 1999;7:130-5.

26. Robinson KM, Christensen KB, Ottesen B, Krasnik A. Diagnostic delay, quality of life and patient satisfaction among women diagnosed with endometrial or ovarian cancer: a nationwide Danish study. Qual Life Res. 2012;21:1519-25.

27. Song H, Fang F, Valdimarsdottir U, Lu D, Andersson TM, Hultman C, et al. Waiting time for cancer treatment and mental health among patients with newly diagnosed esophageal or gastric cancer: a nationwide cohort study. BMC Cancer. 2017;17:2. 